\title{
El periodismo informativo y la televisión infantil en las primeras temporadas de la serie de ficción televisiva Los Simpson
}

\section{Informative journalism and the children's television in the first seasons of The Simpsons}

\author{
Carmen Marta-Lazo \\ Profesora Titular de Periodismo \\ (Universidad de Zaragoza) \\ Francisco Javier Ruiz del Olmo \\ Profesor Titular de Comunicación Audiovisual \\ (Universidad de Málaga) \\ Alejandro Tovar Lasheras \\ Doctorando en Comunicación \\ (Universidad de Málaga)
}

Departamento de Comunicación Audiovisual y Publicidad

Fecha de recepción: 27 de enero de 2017

Fecha de revisión: 22 de junio de 2017

Fecha de publicación: 1 de julio de 2017

Para citar este artículo: Marta-Lazo, C., Ruiz del Olmo, F. J. y Tovar Lasheras, A. (2017):

El periodismo informativo y la televisión infantil en las primeras temporadas de la serie de ficción televisiva Los Simpson, Icono 14, volumen 15 (2), pp. 92-113. doi: 10.7195/ri14. v15i2.1057 


\section{ARTÍCULOS DE INVESTIGACIÓN}

\section{Resumen}

Los Simpson se ha convertido en una de las series de ficción más singulares y emblemáticas de las últimas tres décadas, así como en un referente en la cultura popular contemporánea. Su visión crítica y paródica, a menudo no exenta de mordacidad, sobre el modo de vida actual y el papel de los medios de comunicación en nuestras sociedades, es una de sus principales señas de identidad. En este artículo, se aborda específicamente la representación en la serie del periodismo informativo y de la televisión infantil, optando por una metodología cualitativa, a través del análisis de discurso. Entre las conclusiones, destaca la función de la televisión como agente socializador, a la vez que medio corruptor de la vida social y cultural. La serie presenta a los informadores, a modo de parodia y crítica social, como personajes alejados de toda ética periodística y a los responsables del entretenimiento y la educación infantil como figuras contrapuestas al correcto desarrollo emocional e intelectual de los niños.

Palabras clave: Los Simpson - Televisión - Medios de comunicación - Periodismo Programación infantil - Crítica social

\section{Abstract}

The Simpsons has become one of the most unique and emblematic fiction series in recent decades, and a benchmark in contemporary popular culture. Its critical and parodic capacity, not often without mordacity, on current lifestyle and the role of the media in our societies is one of its qualities. This article specifically addresses the representation in the series of informative journalism and children's television, opting for a qualitative methodology, through the analysis of speech. Among its conclusions, it highlights the role of television as socializer while corrupter of the social and cultural life stands. The show presents the informers, by way of parody and social criticism, as characters away from any journalistic ethic and those responsible for entertainment and child education as figures opposed to the correct emotional and intellectual development of children.

Key Words: The Simpson - Television; Mass media - Journalism - Teleducation Children's programming - Social criticism 


\section{Introducción}

"Si no hubieran existido, el planeta habría sido destruido por un holocausto hace mucho tiempo. Este es el show que nos ha mantenido vivos y riendo en vez de matando". Son palabras de David Mirkin, productor de la serie televisiva Los Simpson desde 1992, pronunciadas en el documental The Simpsons 20th Anniversary Special (Spurlok, 2010). Sin duda, una sentencia un tanto exagerada, aunque para muchos seguidores fieles de esta serie imaginar la vida sin esta saga sería equiparable a pensar en un mundo sin electricidad, dada su profunda imbricación en la cultura popular contemporánea. Esta serie ha sido reconocida como uno de los mejores programas de televisión de todos los tiempos por la revista Time y ha redefinido el concepto de éxito global, emitiéndose en más de noventa países y siendo traducida a más de cuarenta y cinco idiomas.

La principal justificación para su análisis es que, tras treinta años en antena, Los Simpson han cosechado muchos otros logros que trascienden a la pantalla: tienen una estrella en el Paseo de la Fama de Hollywood, una atracción en los Estudios Universal de Orlando y una recreación a escala real de la casa familiar en Las Vegas. Incluso el mundo hoy habla el idioma Simpson: la onomatopeya d'oh! fue adoptada como palabra en el año 2001 y oficialmente añadida al Oxford English Dictionary, definida como "Expressing frustration at the realization that things have turned out badly or not as planned, or that one has just said or done something foolish". Los Simpson llevan tanto tiempo en pantalla que ya son todo un referente y nadie pone en duda que han conseguido cambiar el paisaje cultural por su profunda revisión paródica, irónica y crítica de la sociedad actual.

Nacieron en 1987 concebidos como cortinilla comercial para The Tracey Ullman Show, un late night de variedades emitido por la Cadena FOX hasta 1990. Era entonces difícil imaginar que terminarían por convertirse en el spin-off más exitoso de la historia de la televisión.

Sus episodios iniciales duraban poco más de dos minutos, pero pronto surgió la idea de dotarlos de entidad propia. Los Simpson debutaron como programa autónomo de veintidós minutos el 17 de diciembre de 1989 con su especial Sin blanca 


\section{ARTÍCULOS DE INVESTIGACIÓN}

Navidad. En 1997 sobrepasaron a Los Picapiedra como la serie de animación estadounidense de mayor permanencia en el prime time y el 6 de noviembre de 2016 la Cadena FOX confirmaba su renovación por dos temporadas más, haciéndola llegar a las $30 \mathrm{y}$ al récord de episodios de las series de animación de las últimas décadas.

"Mi objetivo siempre fue invadir la cultura pop, comprobando hasta dónde podía llegar", explicaba Matt Groening, padre de Los Simpson, también en el especial emitido con motivo del vigésimo aniversario de la serie (Spurlok, 2010). La crítica mordaz, el lenguaje desenfadado, la osadía de abordar cualquier tema sensible y la ironía que impregna todos los guiones han sido las fórmulas, en lo que a narrativa respecta, con las que Los Simpson han conseguido permanecer impertérritos en las programaciones de decenas de cadenas de televisión de cualquier latitud del mundo. Los propios medios de comunicación, singularmente la televisión y sus programas, han sido caricaturizados en numerosas ocasiones, entre la parodia y la crítica.

En ese sentido, el presente artículo tiene como objetivo analizar la representación que en esta serie televisiva se hace de los medios de comunicación en su vertiente informativa, infantil y de entretenimiento, y la función que juega en los hábitos y rutinas de los habitantes de Springfield, la ciudad estadounidense ficticia en la que vive la familia Simpson. De este modo, estudiaremos el contenido de las informaciones ofrecidas a través de la televisión, los aspectos formales utilizados, las actitudes de los presentadores televisivos, a través de la figura del conductor de informativos Kent Brockman y del ídolo infantil Krusty, el Payaso, y sus dibujos animados de cabecera, Rasca y Pica, entre otros personajes.

En cuanto a las hipótesis, nos proponemos dar respuesta a las siguientes:

- Uno de los hilos conductores nucleares de la serie Los Simpson es la televisión, siendo una metacrítica al poder que ejerce el medio en la masa de televidentes que no ponen en tela de juicio ni la certeza ni la calidad de las informaciones, sino todo lo contrario.

- Los presentadores de televisión cuestionan, mediante una caricatura satírica, los arquetipos de mala praxis profesional, que priman la subjetividad, el 
El periodismo informativo y la televisión infantil en las primeras temporadas... | 96

ARTÍCULOS DE INVESTIGACIÓN

sensacionalismo, el partidismo tendencioso y la preocupación por los altos índices de audiencia para conseguir ingresos millonarios, obviando todas las premisas deontológicas del periodismo.

- Los programas infantiles parodian los contravalores en los que se educa a los niños a través de la televisión, el consumo, la fama y la agresividad que caracteriza la sociedad actual.

\section{Material y método}

En primer lugar, cabe señalar que Los Simpson es una serie muy poco estudiada desde la vertiente del análisis del discurso. Tan sólo algunos autores se han ocupado de ello (Gómez Morales, 2013; Salazar, 2015) poniendo de manifiesto “la perdurabilidad de los mensajes difundidos en Los Simpson frente a conocidas películas que tratan temas sociales, cuyo recorrido en la mente de la audiencia no resulta tan duradero ni provechoso como en el fenómeno mediático promovido por Groening" (Grandío, 2008: 12). Además, existe un evidente vacío de investigaciones que se ocupen de analizar la representación de los medios de comunicación y el periodismo en la serie, si bien otras series de ficción televisiva como South Park o Padre de familia han sido analizadas a este respecto (Mollejo, 2016; RodríguezVirgili, Sádaba y López-Hermida, 2010).

Son más abundantes los estudios sobre Los Simpson abordados desde otras perspectivas. Diferentes autores se han ocupado de analizar en la serie cuestiones de género (Analuisa, 2015; Reig y Mancinas, 2010; Chacón y Sánchez-Ruiz, 2009, Henry, 2007; Feltmate y Brackett, 2014), las claves de su éxito (Marta-Lazo y Tovar, 2011; Gray, 2006), las técnicas utilizadas para traducir su humor (Lorenzo; Pereira y Xaobanova, 2003), su relación con las ciencias económicas (Chu, 2014; Lucassen y Thomas, 2010) y otros aspectos relacionados con la psicología y la espiritualidad (Feltmate, 2013; Eaton y Uskul, 2004; Pinsky, 2001), aunque las líneas de todos ellos difieren de los objetivos marcados en el presente estudio.

Por otro lado, encontramos también numerosos análisis relacionados con el consumo de series de ficción televisiva (Aguaded, 1999; Huertas y França, 2001; 


\section{ARTÍCULOS DE INVESTIGACIÓN}

Montero, 2006), sobre todo por parte de los niños y adolescentes, atendiendo a su incidencia en la configuración de su personalidad y de los valores que estas imprimen en sus etapas de crecimiento intelectual y evidenciando cómo “la adolescencia es un tiempo que se caracteriza por el incremento en la autoconciencia, por lo que son especialmente sensibles a las imágenes que provienen de los medios. Esas imágenes son utilizadas como fuente de información y comparación en la búsqueda de su identidad" (Pindado, 2006: 13).

Los Simpson emite en Estados Unidos a fecha de 2017 su temporada veintiocho, con un promedio de veintidós capítulos por cada una de ellas. Como muestra de nuestro estudio, acotaremos el trabajo de campo a las ocho primeras temporadas, con el análisis de 178 capítulos.

Esta elección se debe, por una parte, a la ingente cantidad de capítulos emitidos y a que se hace imprescindible seleccionar una muestra. Por ello, nos decantamos por los primeros años la serie, cuando contaba con un sello original ofrecido por el equipo primigenio. Y realizamos el filtro en la novena temporada, puesto que es entonces cuando cambia el equipo del productor ejecutivo Mike Scully y se modifican los patrones de conducta originales de sus personajes, como subrayase el crítico de cine y televisión Scott (2001) en un artículo publicado por The New York Times. El también crítico televisivo Suellentrop (2003) reforzaba esta idea en otro artículo para Slate Magazine, en el que aseguraba que "a pesar de que los fans, críticos y miembros del equipo se regocijan de la longevidad del programa, todos ellos están de acuerdo en que las pasadas cinco o seis temporadas se han esfumado".

Lejos de pretender observar los posibles factores determinantes de la merma de calidad de Los Simpson, estas evidencias sirven para delimitar la muestra que se analizará en el presente artículo y que abarca, como ya se ha explicado, los episodios emitidos desde 1989 hasta 1997. Este momento coincide con la desvinculación de Matt Groening del trabajo diario en la producción, puesto que en 1997 comienza a embarcarse en la creación de otra serie de animación para adultos, Futurama, estrenada en 1999. 
Con el objetivo de centrar nuestro objeto de estudio, se ha atendido a una de las principales carencias temáticas que no se suelen abordan de manera habitual en este tipo de series televisivas: los asuntos relacionados con la información y el periodismo y los relativos a la representación de la televisión infantil.

Los parámetros de análisis que se han definido para analizar la representación del periodismo informativo en Los Simpson son el tratamiento sensacionalista de las noticias en televisión, así como su presentación teatralizada; la subjetividad y el alejamiento del código deontológico de los presentadores responsables de la labor de información y el posicionamiento de estos como "figuras de culto", como prescriptores de tendencias más que como elementos imparciales del proceso informativo, estando todos estos parámetros relacionados íntimamente con la exigencia por parte de las cadenas de televisión de ganar mayores cuotas de audiencia que, a la postre, se traducen en mayores beneficios.

En cuanto al análisis del reflejo en la serie de los contenidos pensados para el público infantil, se han establecido como indicadores la representación de la violencia en las series de animación y en la figura del showman presentador de contenedores de espacios para menores, atendiendo a los contravalores con los que este instruye a los niños a través de la televisión.

Como método, aplicaremos la técnica cualitativa de análisis de discurso compuesta, como asegura Sayago (2013: 3), "por la convergencia de diferentes ciencias (lingüística, sociología, antropología, psicología social, psicología cognitiva, ciencias políticas, ciencias de la comunicación, pedagogía, etcétera)". Por eso, "es un mecanismo de análisis potente y preciso, que resalta por su ductilidad".

La complejidad teórica del análisis de discurso permite constituir categorías y subcategorías que se adaptan con facilidad a cualquier trabajo de investigación, por lo que se entiende que es la más adecuada para el presente artículo. Como argumenta Santander (2011: 215), "no existe la técnica, pero en el análisis de discurso todo es dinámico". 


\section{ARTÍCULOS DE INVESTIGACIÓN}

De esta forma, se establece el análisis de discurso como la técnica más adecuada para desentrañar y establecer conclusiones sobre los asuntos relevantes que se vayan detectando en los episodios de Los Simpson que componen la muestra objeto de estudio.

\section{Resultados y discusión}

La serie de Matt Groening nació en 1989 concebida como una caricatura ácida y satírica de la sociedad estadounidense y con la pretensión de hacer extensiva esa presentación irónica a todos los países occidentalizados. Sus guiones beben de las construcciones sociales imperantes desde mediados del siglo $\mathrm{XX}$, teniendo a la cultura pop y al papel que desempeñan los mass media (prestando especial atención a la televisión) como principales fuentes para sus tramas.

Educación, ecología, tradiciones, religión, familia... no hay ningún asunto con el que Los Simpson no se hayan atrevido y el carácter universal de esta serie constituye una de las claves del reconocimiento internacional cosechado. Dettmar (2004: 88) etiqueta la serie como "el espectáculo más coherente e intelectualmente irónico de la televisión", posicionando a ese afán satírico como el principal ingrediente de su éxito. Por su parte, Alberti (2004: 24) habla del "uso de la iconografía, la identificación con la alta y la baja cultura y su catalogación en el marco de la cultura pop dominante" como las principales razones para justificar su interés y estudio.

En el caso de la serie que nos ocupa, a diferencia de otras de su género, si hay un tema que goza de especial atención y que es objeto de crítica de manera recurrente a lo largo de sus temporadas es el de los medios de comunicación, prestando especial atención a la televisión y a su papel como medio informativo, de entretenimiento y de espectáculo. Una temática que, sin embargo, no se ha abordado en estudios científicos.

Antes de iniciar el análisis de esta representación a lo largo de las ocho primeras temporadas de la serie, conviene prestar atención al único elemento común a todos los episodios, su cabecera, puesto que constituye una declaración de intenciones 
El periodismo informativo y la televisión infantil en las primeras temporadas... $\mid 100$

ARTíCULOS DE INVESTIGACIÓN

que explica, sin palabras, los fundamentos de todas sus tramas y el papel que cada personaje tiene asignado. Como afirmó el propio Matt Groening: "Los Simpson es un programa de televisión que te recompensa cuando le prestas atención" (Spurlok, 2010). Y su punto de vista está avalado por otros autores. Irwin, Conard y Skoble (2009: 18) aseguran que "la serie es lo bastante profunda e inteligente para garantizar cierto nivel de discusión filosófica".

La primera realidad que el espectador puede constatar observando su cabecera es que Los Simpson defiende a la familia como institución y como refugio de la sociedad contemporánea. Homer, Marge, Bart, Lisa y Maggie conforman un "equipo" que, aunque claramente disfuncional, es también nuclear. Charlas alrededor de la mesa, asistencia semanal a la iglesia, viajes familiares y, sobre todo, largas sesiones de reunión en torno al electrodoméstico estrella de su hogar: la televisión. Y este es, precisamente, el hilo conductor de la cabecera de entrada a cada episodio.

La apertura constituye la carta de presentación de los personajes principales, del entorno en el que viven y de su manera de afrontar sus tareas y ocupaciones. Nos anuncia que Bart es un joven revoltoso que termina todas sus jornadas escolares castigado por una $\mathrm{u}$ otra travesura; que Homer es un hombre negligente $\mathrm{y}$ despistado, puesto que abandona apresuradamente su trabajo de altísima peligrosidad en una central nuclear sin reparar en que una barra de plutonio altamente radioactivo ha quedado adherida a su espalda; que Marge responde al patrón de una ama de casa sobre la que recaen las tareas del hogar y que Lisa es un espíritu libre, creativa y con inquietudes culturales.

Sin embargo, hay algo que les une, un hilo invisible que hace que todos los personajes, pese a sus roles asignados, responsables o irresponsables, negligentes o diligentes, ignorantes o cultivados, abandonen súbitamente sus ocupaciones y corran, literalmente, a reunirse en una misma sala. Y ese elemento es la televisión. Alberti (2004: 298) subraya que "ningún programa dijo nunca antes tanto sobre la propia televisión - su historia, sus convenciones formales y su impacto social - como Los Simpson".

Springfield, la ciudad imaginaria en la que habitan los personajes, se presenta como una suerte de falansterio moderno. Una vez disipadas las nubes que dan ini- 
cio a la presentación de la serie, se observa cómo el único elemento que sobresale de manera notable en su skyline es la Central Nuclear; es la industria que somete al pueblo que, además, está construido en un valle y rodeado por montañas, en lo que podría ser una alegoría de su cerrazón cultural y de pensamiento. Martín Correa (2006: 36) subraya que "Springfield conserva una estructura urbana consecuente con la arquitectura del siglo XIX, época en que la revolución industrial ya tenía una creciente influencia en la forma de habitar las poblaciones. El pueblo que habitan los Simpson gira en torno a una fábrica, siendo esta el factor clave de su ordenamiento urbano $\mathrm{y}$, por ende, de su organización social".

De este modo, la única ventana que los Simpson tienen hacia el mundo exterior es la televisión. Aunque la programación televisiva está lejos de ser una ventana a otras realidades, como se puede deducir del análisis de discurso de los capítulos que componen el diseño muestral del presente artículo, el cual presentamos en los siguientes epígrafes.

\subsection{El periodismo informativo y su estrella mediática, Kent Brockman}

El pueblo de Springfield, como ya se ha apuntado, se retrata como un lugar localista y aislado de influencias exteriores. Por ello, no es de extrañar que la cadena de televisión más popular del panorama mediático springfieldiano es su propia emisora local, el Canal 6. Todos acuden a ella para estar informados, tarea que recae con carácter de exclusividad desde los años 70 (según podemos deducir del episodio Madre Simpson, T7. E8) en el afamado Kent Brockman, de quien Dan Rather, histórico periodista de los servicios informativos de la cadena estadounidense $C B S$, dijo: "no sabría exactamente qué decir sobre él, pero sí tengo claro que lo contrataría" (Spurlok, 2010). Brockman es el presentador de todos los programas informativos de la Televisión Simpson: además de los noticiarios habituales, asume la dirección del programa de reportajes 0jo en Springfield, del de debates de actualidad Línea Inteligente y del espacio de informaciones de impacto Noticias de acción. A través del polifacético personaje, se observa cómo la serie pretende ridiculizar el culto a la figura del presentador de noticias, cómo ironiza sobre la presentación subjetiva de las informaciones, cómo los contenidos morbosos han ido comiendo terreno a 
las noticias e investigaciones serias y cómo algunos informativos pretenden obtener una mayor cuota de pantalla aportando una importancia exagerada a noticias del todo fútiles.

\subsubsection{El presentador como figura de culto}

Kent Brockman es el paradigma de conductor de informativos que se implica en la noticia, la hace suya, llegando incluso a participar de ella. El veterano presentador de la $N B C$ Briam Williams habla de él como un profesional que lo tiene todo controlado: "Si puedes falsear la vida y ofrecérsela al hombre medio tal y como este espera recibirla, tienes todo el trabajo hecho. Esa es la filosofía de Kent" (Spurlok, 2010). Y explota ese savoir faire aplicando herramientas artísticas y convirtiéndose en un auténtico actor, porque también sabe, como asegura Calabrese (2000: 44), que "el culto a la personalidad es un elemento esencial del sensacionalismo en los informativos".

De esta forma, podemos ver cómo cambia su atuendo cuando la ocasión lo requiere, como hace durante su visita al Kampamento Krusty en el episodio Kampamento Krusty (T4. E1), momento en el que aparta su habitual traje por una camisa de aventurero, o cuando realiza una conexión en directo desde la casa de los Simpson mientras está siendo pasto de las llamas, llegando a ensuciarse la cara con unos tizones para aparentar una mayor implicación con el suceso (Homer, el hereje, T4. E3).

Sabe que es la cara visible del Canal 6 y que su sueldo depende directamente de su fama, por lo que no permite que nadie le haga sombra. Nadie, ni siquiera los colaboradores de su informativo, como el reportero Arnie Pye, encargado de dar la información del tráfico desde un helicóptero, y al que Brockman no permite hablar más de un par de minutos seguidos queriendo evitar que le robe el protagonismo.

\subsubsection{El sensacionalismo por bandera}

Lo cierto es que Kent Brockman es un fiel reflejo del proceso sensacionalista vivido por muchos noticiarios en las últimas décadas. Bob Franklin (1997) asegura que el escándalo y el sobredimensionamiento de la noticia se ha convertido en norma para muchos periodistas, y que el entretenimiento ha sustituido a la infor- 
mación; el interés humano ha reemplazado el interés público; el juicio mesurado ha sucumbido ante el sensacionalismo y lo trivial ha triunfado sobre lo relevante. Y eso Brockman lo sabe y lo domina.

Por ello, todos los contenidos de su programa El Ojo en Springfield, el espacio de reportajes de actualidad sobre la ciudad, están vinculados a temas que apenas están en la agenda de los medios tradicionales u otros asuntos menores, marginales o de carácter sensacionalista, como una conversación entre el hombre más viejo con el hombre más gordo de Springfield. La cabecera del espacio ya aporta pistas sobre su línea argumental, plagada de contenidos superficiales e, incluso, con una mirada machista: se ve al presentador apostando en el canódromo acompañado de atractivas mujeres o bañándose en un jacuzzi mientras unas jóvenes japonesas le dan de comer sushi directamente en su boca.

Además, es un buscador incansable de noticias cargadas de sesgo sensacionalista para despertar las emociones del telespectador, dado que sabe el impacto que causan este tipo de enfoques y temas en la audiencia. Esta tendencia queda patente en el capítulo Bart en el Día de Acción de Gracias (T1. E7), en el que Brockman elabora un reportaje en el comedor social de Springfield. A su salida, agradece a los mendigos su participación diciéndoles: “Este periodista se está oliendo otro Premio Emmy".

No duda en modificar su escaleta para abordar determinados temas, siempre y cuando le sirvan para contagiarse de su buena aceptación social o de su bonhomía. En el capítulo Lisa contra Stacy Malibú (T5. E14), Lisa se propone lanzar una línea de juguetes para niñas que representen los que para ella son valores ideales de la mujer moderna. Alarmada por las soflamas machistas que su muñeca Stacy Malibú está inculcando en su generación ("A mí no me preguntes, sólo soy un chica”, “Olvidemos los problemas con un gran bol de helado de fresa", etc.), decide fabricar su propio prototipo y lanzarlo al mercado, pero utilizando en su diseño una imagen más vinculada a los valores de igualdad de sexos y con frases como "Cuando me case, conservaré mi apellido". Kent recibe noticia de esa información y, aunque es reticente en un primer momento, decide dedicar un programa completo a hablar de “Lisa, Corazón de León" (el nombre del nuevo juguete), aunque no lo hará pen- 
sando en aportar su ayuda a la lucha contra las diferencias de género, sino que lo utilizará para posicionarse como un periodista sensible a estos temas aunque, en el fondo, le resulten intrascendentes.

\subsubsection{Presentación subjetiva de la información}

La objetividad e imparcialidad son valores que brillan por su ausencia en la mente de Brockman. En ninguno de los debates que presenta en Línea Inteligente, es capaz de ejercer únicamente de moderador. Ejemplo de ello es el programa que aborda si la serie de dibujos animados Rasca y Pica es o no adecuada para el público infantil, dados sus altos índices de violencia gratuita (Rasca, Pica y Marge, T2. E9), en el que Kent no duda en posicionarse del lado de los defensores del show impidiendo que Marge, la única defensora de la tesis de que el programa debería ser calificado para mayores de edad, tome la palabra, y criticando en todo momento sus consideraciones.

Sin embargo, Brockman no es el único exponente del periodismo sensacionalista que aparece en Los Simpson. En el episodio Homer, hombre malo (T6. E9), Homer es acusado de acoso sexual por la canguro de sus hijos. Aunque no es culpable de tal delito, es sometido al escarnio público y se ve obligado a permanecer recluido en casa, donde recibe la llamada telefónica de Godfrey Jones, presentador del programa de reportajes Lo más bajo, quien le promete que hará todo lo posible por ayudarle a limpiar su imagen. No obstante, sus intenciones son otras: pretende presentar a Homer como un obseso sexual, a pesar de saberle libre de toda culpa, y lo consigue editando una entrevista exclusiva que éste le concede. De esta forma, se aborda el tema de la tergiversación y manipulación informativa, a través de la creación de falacias.

\subsubsection{Exposición sensacionalista de la información}

El presentador es un auténtico genio de la especulación y la tergiversación de informaciones, pero también demuestra unas dotes teatrales indiscutibles. Sirva como ejemplo el programa informativo Noticias de acción (Lisa sobre hielo, T6. E8). Brockman hace su aparición en el plató saltando súbitamente sobre su silla y exponiendo la información de una manera tremendista. Comienza anunciando a los 
espectadores que “podrán ver la tremenda explosión... en el precio de la madera. Pero antes, hagamos el balance de muertos provocados por la asesina tormenta que nos golpea con su metralleta cargada de nieve", a lo que el presentador del tiempo responde con que la cifra es cero, asegurando no obstante que pronto subirá por las nubes. El periodista utiliza en todo momento un tono de voz muy alto, describe movimientos rápidos y gestos agresivos, acercándose y alejándose de la cámara. Todo para ocultar una realidad: carece de noticias de interés, algo que la audiencia no tiene que percibir porque, ante todo, el objetivo es que no cambien de canal.

\subsubsection{Discusión}

En resumen, como asegura Gómez Morales (2013: 731), la imagen del presentador de servicios informativos actual vinculado a los criterios de "profesional reflexivo, conocedor, asertivo, honesto, responsable, imparcial y comedido cede paso a un modelo de periodista que desmitifica la figura del presentador de noticias, invierte los criterios de valoración periodística, seduce a la audiencia con sus dotes interpretativas, editorializa las noticias y es capaz de exagerar el hecho más nimio hasta hacerlo pasar por una noticia de máxima relevancia". Así, Los Simpson son el fiel reflejo de la crítica al periodismo audiovisual sensacionalista cada vez más presente en el panorama televisivo occidental.

\subsection{La televisión infantil de los niños Simpson}

Si el periodismo informativo tiene un principal adalid en la Televisión Simpson, el entretenimiento catódico infantil cuenta también con un nombre propio: Krusty, el Payaso. Y, como en el caso anterior, el mayor referente también representa, de manera exagerada, la antítesis de los valores que se deberían esperar de él. Herschel Krustofsky es alcohólico, analfabeto (según confiesa él mismo en el capítulo Krusty entra en chirona, T1. E12), aficionado a la pornografía, tirano con sus empleados y de una ambición desmedida por el dinero. Sin embargo, este currículum, lejos de suponerle un impedimento para presentar el programa infantil más seguido por los niños springfieldianos, le ha convertido en el presentador estrella de este target.

Alcanzar la fama es su único propósito y ha logrado convertir a su audiencia en "masa aborregada" que consume todo lo que su referente les ofrece sin criticarlo. 
De hecho, arranca sus shows preguntando a sus seguidores cuánto le quieren y qué harían si su programa desapareciera de la televisión, a lo que todos los niños, al unísono, responden que se suicidarían (Krusty entra en chirona, T1. E12). En Krusty, confían los padres de Springfield gran parte de la educación de sus hijos, sin importarles lo alejadas que están sus enseñanzas de cualquier criterio de excelencia o responsabilidad. De ahí que niños como Bart Simpson crezcan guiados por unos patrones de conducta basados en "contravalores": "Bart ve en su ídolo el modelo perfecto de lo que él anhela ser en la vida: una estrella del humor, materialista, adinerado, famoso, cruel y poderoso" (Martín Correa, 2006: 152).

\subsubsection{Rasca y Pica, caravana animada de violencia}

El Show de Krusty está impregnado de enseñanzas que suponen la antítesis de la buena educación, obviamente para ponerlas en entredicho. Su contenido estrella es El Show de Rasca y Pica, una mini-serie que narra las constantes peleas entre un ratón y un gato, siendo este último el que siempre termina muriendo de la manera más cruel y cruenta posible.

Ningún adulto muestra preocupación ni adopta decisiones al respecto. Únicamente Marge, de manera aislada, encabeza una cruzada para prohibir la tira de Rasca y Pica, tratando de implicar a la comunidad educativa de Springfield. En el capítulo Rasca, Pica y Marge (T2. E9), la madre de los Simpson queda estupefacta al observar la violencia gratuita que el gato y el ratón promocionan en un programa supuestamente infantil. Al preguntarse “¿qué clase de pervertido puede encontrar gracioso esto?", observa cómo Homer se está aguantando la risa a sus espaldas. Tras conseguir la modificación de los guiones de la tira cómica, el capítulo concluye con una vuelta al inicio y a la reposición de los mismos patrones de extrema violencia en la mini-serie.

De esta forma, se advierte que cualquier lucha resulta inútil. En un capítulo posterior, la factoría de Rasca y Pica inaugura un parque temático sobre la serie bajo el eslogan "El lugar más violento de la tierra", invitando a las familias a disfrutar de una jornada plagada de juegos relacionados con las armas, las peleas y el dolor (Rascapiquilandia, T6. E4). Homer y Marge, lejos de apartar a sus hijos de una influencia tan nefasta, deciden organizar un viaje en familia para visitar el espacio de recreo. 


\section{ARTÍCULOS DE INVESTIGACIÓN}

\subsubsection{Discusión}

El Show de Krusty y sus contenidos son el reflejo crítico de los contravalores que se vinculan con la falta de calidad en la televisión infantil, lo que sería un mal referente para los niños.

Después de realizar un repaso por el tipo de contenidos que la televisión emite para la audiencia infantil y de la violencia que introducen esos programas, Urra, Clemente y Vidal (2000: 203) concluyen que los niños y jóvenes son considerados más como unidades de consumo que como ciudadanos con derecho a recibir educación o formación: “La televisión es violenta y los niños, al igual que los mayores, están siendo socializados en valores que hacen que la violencia no sea sino un instrumento para alcanzar los fines deseados".

Precisamente, uno de los aspectos que cabría plantearse es la correcta clasificación de Los Simpson, una serie para público familiar, debido a que tiene varios niveles de lectura y llegar a interpretar el trasfondo crítico no resulta fácil. En una investigación realizada por Marta-Lazo (2005: 269) con menores de 7 a 12 años, en grupos de discusión, ante el visionado de un fragmento de un capítulo en el que Bart y Homer están viendo un programa violento de televisión, se pudo comprobar que los niños ponían en tela de juicio que ese tipo de contenidos fuera destinado a ellos, con los siguientes argumentos: "el hecho de que Homer le deje ver esa serie a Bart es brutal", "es un poco bélico que se maten a tortas, es una burrada", "eso está muy mal, ya no me gustan tanto Los Simpson". Estas afirmaciones se derivan del visionado de una secuencia extractada de la serie, lo que suponen interpretaciones propias de un segmento del público que está acostumbrado a ver Los Simpson de forma continua sin tener una mirada crítica. Por ello, como apunta Marta-Lazo (2005), habría que reconsiderar la calificación de Los Simpson.

Los contenidos audiovisuales, entre ellos la serie que nos ocupa, a través de un despliegue cada vez mayor de plataformas, tales como los canales temáticos de televisión, apps o YouTube Kids, tienen un papel fundamental en la educación de los menores. Como asegura Cáceres (2006: 6), “Ante esto, la educación formal no puede permanecer pasiva $\mathrm{y}$, por consiguiente, se impone llevar a cabo una auténtica alfabetización que forme receptores críticos y preconice un consumo racional de los mismos". 
El periodismo informativo y la televisión infantil en las primeras temporadas... | 108 ARTíCULOS DE INVESTIGACIÓN

\section{Conclusiones}

“No culpes a nuestra generación de tener tan poca capacidad de atención. Nos pasamos la vida frente al televisor". Puede que esta sea una de las frases que mejor condensan el papel que desempeña la televisión para la sociedad representada en Los Simpson. La sentencia fue pronunciada por Lisa (Me casé con Marge, T3. E12) quien, a pesar de sus inquietudes culturales, no puede luchar contra el efecto atrayente del electrodoméstico estrella de los springfieldianos. No puede luchar porque está atrapada y porque, además, nadie va a ayudarle a hacerlo en vista de lo que su padre, Homer Simpson, le responde entre dientes: "No vuelvas a hablar así de la televisión".

Así, hemos podido concluir que todo en la vida de la familia Simpson gira en torno a la televisión, de tal modo que es una metacrítica directa al medio que, precisamente, la ha encumbrado como serie de fama internacional. Marca sus agendas, les ayuda a establecer sus horarios y es, a la postre, lo que les mantiene unidos. Sirva como ejemplo de ello el episodio El amante de madame Bouvier (T5. E21): toda la familia, incluyendo al abuelo, Abraham Simpson, a las hermanas de Marge, Patty y Selma y la madre de las tres, Jaqueline Bouvier, se reúnen en la casa familiar para celebrar el primer cumpleaños de Maggie. Sentados en torno a la mesa y mientras disfrutan de una conversación en la que rememoran situaciones de otros cumpleaños, los dos abuelos recuerdan con cariño la "simpática canción" que Bart y Lisa cantaron a dúo en el tercer cumpleaños de esta. Al volver a interpretarla, caen en la cuenta de que es el jingle de un spot de televisión, por lo que Lisa, preocupada, pregunta: “¿Es que no sabemos más que canciones de anuncios?". Tras un segundo de silencio y un intercambio de miradas, el resto de los familiares responden coreando la canción mientras la bailan alrededor de la mesa.

La televisión también hace mella en su vida social y cultural y les impide desarrollar muchas otras actividades, hecho que queda patente en el capítulo Secretos de un matrimonio con éxito (T5. E22). Homer está dolido con sus amigos por haber menospreciado su velocidad mental. Comentando lo sucedido con su mujer, Marge le dice que sus inquietudes culturales son bastante escasas, a lo que este contesta: “ $¿ Y$ crees que no quiero cultivarme? Son las malditas cadenas de televisión, ¡no me dejan! Un magnífico programa tras otro, cada uno mejor y más interesante que el anterior... ¡No me dejan vivir!". 
De este modo, se advierte cómo los Simpson han dotado a la televisión de un papel dominante y la han convertido en su única ventana al mundo, llegando a convertirse en seres alienados que obedecen todos sus dictados, sin plantearse si la información que les ofrece es o no correcta. De ahí que los rostros mediáticos que representan en la serie a los presentadores de informativos, a los showmans y a los educadores infantiles gocen de ese poder de persuasión y de influencia, hecho que ellos conocen y explotan sin pudor, con la finalidad de parodiar la televisión actual.

En definitiva, y en apariencia, Los Simpson dibujan a un presentador de informativos de gran veteranía y a un payaso aparentemente inofensivo que entretiene a los menores con juegos de malabares.

No obstante, todos los ejemplos reseñados definen a Kent Brockman como un periodista adalid de la subjetividad, defensor del sensacionalismo y del partidismo tendencioso ante cualquier información; un narcisista más preocupado por engrosar su billetera y por mantener unos altos índices de audiencia que por acercar a sus convecinos la realidad y la noticia objetiva; un "profesional" del medio que perdió hace mucho tiempo cualquier vínculo con el código deontológico periodístico y que hoy en día únicamente se guía por el morbo y la escatología informativa.

Los episodios analizados también han ayudado a conocer el perfil de un presentador infantil despreocupado por el correcto desarrollo emocional e intelectual de sus seguidores, al que también únicamente le interesa amasar gran cantidad de dinero para seguir manteniendo una vida licenciosa; un payaso violento y sibarita que pone en peligro la estabilidad de la sociedad del futuro formando hoy a los que serán los adultos de mañana bajo el patrón de una escala de valores alejada de cualquier criterio de responsabilidad.

Los Simpson también se burla de la preponderancia que la televisión tiene en las vidas de los occidentales sobre cualquier otro medio de comunicación, más allá de los personalismos que la construyen. La serie utiliza a los springfieldianos $\mathrm{y}$, en particular, a los Simpson, para ridiculizar nuestros patrones consumistas, nuestra falta de análisis, criterio y filtro a la hora de contrastar y validar las informaciones que nos ofrecen los noticiarios y a la negligencia de muchos adultos que no se preocupan por los contenidos que están marcando el desarrollo intelectual de sus hijos. 
Los Simpson viven en un pueblo aislado de cualquier influencia exterior, por eso la televisión goza de un respeto tan desmesurado, porque todo lo que les haga escapar de una existencia fútil e insustancial es recibido con aplausos. Homer, Marge, Bart, Lisa e incluso la pequeña Maggie no podrían entender una vida sin televisión. De hecho, en el capítulo Hogar, agridulce hogar (T1. E4), ante una falta de liquidez puntual, Marge propone empeñar su sortija de compromiso antes de desprenderse del televisor.

En el supuesto de que no existiera esa válvula de escape a una existencia insustancial, los Simpson no podrían soportarlo. De hecho, el peor de los escenarios que pueden imaginar es precisamente ese: un día sin poder refugiarse en sus programas. En el episodio El último resplandor del actor secundario Bob (T7. E9), el antiguo ayudante de Krusty, Bob Terwilliger, amenaza con detonar una bomba nuclear si no se termina con la televisión en Springfield. En un gabinete de crisis liderado por el alcalde Joe Quimby, el Jefe de Policía Clancy Wigumm y Krusty, este último exclama: “¿Creen que merecería la pena vivir en un mundo sin televisión? ¡Los vivos envidiarían a los muertos!".

De esta forma, podemos concluir que hemos confirmado las hipótesis planteadas porque la televisión supone para Los Simpson, como ya se advierte en su propia cabecera, el eje central de la serie, uno de los principales nexos de unión para sus personajes y, sobre todo, un hilo conductor para parodiar la sociedad actual y el poder que emana de los medios de comunicación. Al mismo tiempo, se pone en evidencia la falta de educación mediática por parte de la ciudadanía para hacer frente a los contenidos de baja calidad que se programan en la pantalla.

Una de las líneas de interés que se abren para futuras investigaciones es profundizar en mayor medida de qué forma reciben los niños este tipo de mensajes que la serie proyecta en forma de parodia y metáforas constantes. Esta serie tiene un discurso muy ácido que requiere una reinterpretación de significado, pues la lectura lineal a veces resulta insuficiente. En este sentido, habría que analizar los diferentes niveles de lectura en relación con tramas metafóricas e hiperbólicas y que no siempre pueden llegar a entender los menores. De este modo, se plantean nuevas posibilidades de investigar desde la recepción las tramas de la serie de animación decana de la televisión. 


\section{ARTÍCULOS DE INVESTIGACIÓN}

\section{Referencias}

Aguaded, J. I. (1999). Convivir con la televisión. Barcelona, Paidós

Alberti, J. (2004). The Simpsons and the possibility of oppositional culture. Detroit: Wayne State University Press.

Analuisa, A. X. (2015). La construcción de estereotipos sobre la familia tradicional en el programa de dibujos animados "Los Simpsons". Quito: Universidad Central de Ecuador.

Cáceres, M. D. (2006). Comunicación y Educación. Un balance cualitativo. Revista Icono14, 7, 1-17. Recuperado de http://tinyurl.com/ycdevtsw

Calabrese, A. (2000). Political space and the trade in television news. Tabloid tales. Global debates over media standards. Nueva York: Lanham, MD, Rownan \& Littlefield.

Chacón, P. \& Sánchez-Ruiz, J. (2009). La estructura familiar de Los Simpsons a través del dibujo infantil. Revista Mexicana de Investigación Educativa, 14(43), 1129-1154. Recuperado de http://preview.tinyurl.com/y77nlfg6

Chu, S-Y. (2014). An assessment of teaching economics with The Simpsons. Internacional Journal of Pluralism and Economics Education, 5(2), 180-196. doi:10.1504/IJPEE.2014.063505

Dettmar, J.H. (2004). Countercultural Literacy: Learning Irony with The Simpsons. En J. Alberti, The Simpsons and the possibility of oppositional culture. Detroit: Wayne State University Press.

Eaton, J. \& Uskul, A. (2004). Using The Simpsons to teach social psychology. Teaching of Psychology, 31, 277-278. Recuperado de https://kar.kent.ac.uk/32400/

Feltmate, D. \& Brackett, K. (2014). A Mother's Value Lies in Her Sexuality: The Simpsons, Family Guy, and South Park and the Preservation of Traditional Sex Roles. Symbolic Interaction, 37(4), 541-557. doi:10.1002/symb.124

Feltmate, D. (2013). It's Funny Because It's True? The Simpsons, Satire, and the Significance of Religious Humor in Popular Culture. Journal of the American Academy of Religion, 81(1), 222-248. doi:10.1093/jaarel/lfs100

Franklin, B. (1997). Newszak and news media. Londres: Arnold.

Gómez Morales, B. M. (2013). La imagen del periodista y el sensacionalismo en la ficción televisiva. El caso de las comedias animadas de prime time. Barcelona: Universitat Autónoma de Barcelona. 
El periodismo informativo y la televisión infantil en las primeras temporadas... | 112 ARTÍCULOS DE INVESTIGACIÓN

Grandío, M. (2008). Series para ¿menores? La realidad que transmite la ficción. Análisis de "Los Simpsons". Sphera Pública, Revista de Ciencias Sociales y de la Comunicación, 8, 157-172. Recuperado de http://tinyurl.com/yccq874q

Gray, J. (2006). Watching with The Simpsons: Television, Parody, and Intertextuality. Abingdon: Routledge.

Henry, M. (2007). “Don't Ask me, I'm Just a Girl”: Feminism, Female Identity, and The Simpsons. The Journal of Popular Culture, 40, 272-303. doi:10.1111/j.15405931.2007.00379.x

Huertas, A., \& França, M.E. (2001). Una aproximación a cómo contribuye la televisión en la construcción del yo. Zer, Revista de estudios de Comunicación, 6, 331-350. Recuperado de http://tinyurl.com/ycya8nre

Irwin, W., Conard, M. T., Skoble, A. J. (2009). Los Simpson y la filosofía. Barcelona: Blackie Books.

Lorenzo, L; Pereira, A. M. \& Xaoubanova, M. (2003). The Simpsons/Los Simpson. Analysis of an audiovisual translation. The Translator: studies in intercultural communication, 9(2), 269-291. doi:10.1080/13556509.2003.10799157

Luccasen, A. \& Thomas, K. (2010). Simpsonomics: Teaching economics using episodes of the Simpsons. Internacional Journal of Pluralism and Economics Education, 41(2), 136-149. doi:10.1080/00220481003613847

Marta-Lazo, C. \& Tovar, A. (2011). Los Simpson, un fenómeno social con 20 años de permanencia en la programación televisiva. Revista Mediterránea de Comunicación, 2, 143-157. Recuperado de http://tinyurl.com/y8qnoll4 Marta-Lazo, C. (2005). La televisión en la mirada de los niños. Madrid: Fragua. Martín Correa, J. P. (2006). Detrás de los Simpson. Barcelona: Laberinto.

Mollejo, V. (2016). Figura del periodista en la ficción televisiva: un análisis mixto de los rasgos distintivos profesionales. Murcia: Universidad Católica de Murcia. Montero, Y. (2006). Televisión, valores y adolescencia. Barcelona: Gedisa.

Pindado, J. (2006). Los medios de comunicación y la construcción de la identidad adolescente. Zer, Revista de estudios de Comunicación, 21, 11-22. Recuperado de goo.gl/3UGTep

Pinsky, M. I. (2001). The Gospel According to the Simpsons: The Spiritual Life of the World's Most Animated Family. Louisville: Westminster John Knox Press 


\section{ARTÍCULOS DE INVESTIGACIÓN}

Reig, R. \& Mancinas, R. (2010). Dibujos animados: estereotipos de género. Revista Latinoamericana de Comunicación Chasqui, 111, 79-83. Recuperado de goo. $\mathrm{gl} / 9$ ugmva

Rodríguez-Virgili, J., Sádaba, T. \& López-Hermida, A. (2010). La ficción audiovisual como nuevo escenario para la Comunicación Política. Cuadernos de Información y Comunicación, 15, 37-54. Recuperado de goo.gl/tGxexi

Salazar, K. P. (2015). La parodia de la política a través de narrativas de las series de televisión: Los Simpson y South Park. Quito: Universidad Politécnica Salesiana.

Santander, P. (2011). Por qué y cómo hacer análisis de discurso. Cinta de moebio, 41, 207-224. Recuperado de http://cort.as/xEUV

Santos, D. A. (2012). La serie animada Los Simpson como una crítica a la sociedad. Un análisis estético comunicativo. Quito: Universidad Politécnica Salesiana.

Sayago, S. (2014). El análisis de discurso como técnica de investigación cualitativa y cuantitativa en las ciencias sociales. Chile: Escuela de Periodismo, Pontificia Universidad Católica de Valparaíso.

Scott, A. 0. (2001). Homer's Oddisey. New York Times Magazine, pp. 42. Recuperado de http://cort.as/xEUi

Spurlok, M. (2010). The Simpsons 20th Anniversary Special: In 3-D! On Ice! Estados Unidos: FOX.

Suellentrop, C. (2003). Who turned best America's TV show into a cartoon? Slate Magazine. Recuperado de http://cort.as/xEUo

Urra, J., Clemente, M., \& Vidal, M. (2000). Televisión: Impacto en la infancia. Madrid: Siglo veintiuno de España editores. 